\title{
When do nonwords activate semantics? Implications for models of visual word recognition
}

\author{
DERRICK C. BOURASSA \\ McMaster University, Hamilton, Ontario, Canada \\ and \\ DEREK BESNER \\ University of Waterloo, Waterloo, Ontario, Canada
}

\begin{abstract}
Three lexical decision experiments examined the conditions in which nonwords activate semantics. Lexical decisions to targets (e.g., CAT) were faster when preceded by semantically related nonword primes (e.g., DEG derived from DOG) when the prime was brief and masked; this nonword priming effect was eliminated when the prime was presented for a longer duration. These results are discussed in the context of both parallel distributed processing models and the idea that the occurrence of nonword priming depends upon subjects being unable to verify the identity of the prime.
\end{abstract}

It is widely assumed that when a word is presented it activates several levels of representation in the reader's mind. When processing is bottom up, the stimulus first activates representations at the letter level, then at the lexical level, and finally at the semantic level (see, e.g., McClelland, 1987). From a phenomenological perspective the reader is not conscious of having performed these different levels of analyses.

Many word recognition models assume that activation from an early stage becomes available to a later stage, regardless of whether processing at the earlier stage is complete. Morton (1969) made this assumption; the logogen model features a set of word detectors that are neither semantically nor associatively linked, and a context system that represents semantics. Morton argued that "the nature of the relationship between the Logogen System and the Context System is such that there is continuous exchange of information between the two" (p. 166). This idea of a continuous flow of activation between stages is also evident in the interactive activation framework (McClelland, 1987; McClelland \& Rumelhart, 1981).

One consequence of this view is that an orthographic and/or phonological pattern that approximates but does not perfectly match a known pattern ought to activate higher order representations associated with that known pattern (although not as strongly as would the known pattern itself). For example, a nonword like DEG ought to activate lexical and semantic representations for DOG. In-

This work was supported by an NSERC doctoral fellowship to D.C.B. and NSERC Grant A0998 to D.B. We are grateful to Jennifer Stolz for a trenchant observation, Steve Joordens for assistance with the simulations, and particularly to Mike Masson for extensive comments and discussion. Correspondence should be addressed to D. C. Bourassa, Psychology Department, McMaster University, Hamilton, ON, Canada L8S 4K1 (e-mail: bourassa@mcmail.cis.mcmaster.ca).

-Accepted by previous editor, Geoffrey R. Loftus deed, there is already good evidence that a nonword activates lexical information corresponding to its real-word neighbors (e.g., Evett \& Humphreys, 1981; Ferrand \& Grainger, 1992; Forster, 1992; Forster, Davis, Schoknecht, \& Carter, 1987; Humphreys, Evett, \& Quinlan, 1990).

It is unknown whether lexical activation produced by a nonword will activate semantics. The experiments reported here speak to this issue. ${ }^{1}$ We begin with a brief review that details some important methodological considerations for the experiments to be reported here.

\section{Methodological Considerations}

Lukatela and Turvey (1994). It is well known that pseudohomophones-letter strings that sound identical to words (e.g., NALE) - produce repetition and semantic priming; for example, NALE facilitates lexical decision times to NAIL (Besner, Dennis, \& Davelaar, 1985) and naming times to FINGER (Lukatela \& Turvey, 1991, 1993, 1994). These results are consistent with the idea that phonology plays an important role in activating semantic-level information. However, because this effect arises from phonological activation produced by pseudohomophones (i.e., there is complete overlap between the phonological codes for NALE and NAIL), it does not directly speak to the question posed here: Does partial orthographic/phonological overlap with a real word produce semantic-level activation?

One way to answer this question is to employ primes that share only partial orthographic/phonological information with known words. Thus, for example, does NALL prime FINGER? Lukatela and Turvey (1994, Experiments 7 , 8 , and 9) included prime-target pairs of this type in order to control for the possibility that pseudohomophone priming may be attributable solely to orthographic overlap between pseudohomophones and their real-word counterparts. They reported no priming effect in this control condition and concluded that the pseudohomo- 
phone priming effect is phonological in nature. More important for present purposes is the fact that the null effect in their control condition argues against the idea that partial orthographic/phonological overlap with a real word produces semantic-level activation. ${ }^{2}$

However, the nonword prime stimuli used by Lukatela and Turvey (1994) provide only a weak test of the partial overlap hypothesis. Although approximately half of the primes differed from their source word by one letter (e.g., NALL from NAIL), the other half of the primes differed from their source word by more than one letter (e.g., BLARD from BLADE). To be fair to Lukatela and Turvey, this discrepancy is a product of their attempt to yoke their control primes with source words and pseudohomophones along a visual similarity dimension; for example, according to Lukatela and Turvey, the control prime BLARD has the same index of visual similarity with the pseudohomophone BLAID as it has with the source word BLADE. Nonetheless, our suggestion is that in order to observe the effects of activation that are of interest here, it is necessary to use primes that have the maximum possible degree of orthographic overlap with their source words (e.g., as in MUDIC from MUSIC).

Rosson (1983, Experiment 1). Rosson (1983, Experiment 1) found that naming times to target words (e.g., SHEEP) were facilitated when the previously named item was a nonword created from a semantic associate of the target (e.g., FAMB from LAMB). Although this finding would appear to provide support for the idea that nonwords activate semantics, Rosson noted that the design of her experiment invites an alternative explanation:

It may be that the activation occurs subsequent to the pseudoword pronunciation, perhaps because the sound of the pseudoword "reminds" subjects of the similar word. If so, the pseudoword priming effect observed in this experiment could be epiphenomenal to the pronunciation process itself. (Rosson, 1983, p. 156)

Despite this problem, Rosson's (1983) finding does provide an interesting contrast to that of Lukatela and Turvey (1994). It remains to be seen, however, whether (nonpseudohomophonic) nonword semantic priming exists under conditions in which (1) nonword primes have high orthographic overlap with their source words and (2) influences due to higher order strategies or expectancies are minimized that is, whether nonword semantic priming is due to "activation" per se. In the experiments reported here, we therefore used word-like nonword primes (DEG as a prime for CAT) to which no response was required. ${ }^{3}$

Lesch and Pollatsek (1993). If nonword semantic priming does exist under the above conditions, a second question is whether the effect depends on the duration for which primes are displayed to subjects. This question is motivated in part by the work of Lesch and Pollatsek. These investigators examined whether naming latencies to word targets (e.g., NUT) were facilitated by prior presentation of homophones of semantic associates (e.g., BEACH from BEECH). A priming effect was observed when primes were briefly presented $(50 \mathrm{msec})$ and masked, but not when primes were presented for a longer duration ( 250 $\mathrm{msec}$ ) prior to the mask. In contrast, when an appropriate prime was used (e.g., BEECH), priming was found in both prime display conditions.

The presence of homophone priming at a brief prime duration suggests that fast-acting, phonologically mediated semantic activation is driven by the incorrect homophone (e.g., BEACH primes NUT). However, with a long prime duration, the word recognition system appears to inhibit activated semantic representations that are inconsistent with the physical stimulus. Exactly how this occurs is left for later discussion. The question of interest here is, if nonpseudohomophonic nonwords activate semantics, does the word recognition system similarly inhibit such activation over time?

The literature reviewed reveals that it is unclear as to whether nonpseudohomophonic nonword priming exists, and whether this effect is dependent on prime duration. ${ }^{4}$ We now discuss these questions in the context of two different approaches to visual word recognition.

\section{Masson's Hopfield Network}

Models of word recognition have historically assumed localist representations (e.g., McClelland \& Rumelhart, 1981; Morton, 1969). That is, it was assumed that each concept is represented as a single node in the system. This idea dates back to the earliest notions about the structure of semantic memory (Collins \& Loftus, 1975; Collins \& Quillian, 1969; Quillian, 1968). However, the last decade has seen the advent of parallel distributed processing (PDP) models (see, e.g., Hinton \& Shallice, 1991; Masson, 1991, 1995; Plaut, McClelland, Seidenberg, \& Patterson, 1996; Plaut \& Shallice, 1993; Rumelhart, McClelland, \& the PDP Research Group, 1986; Seidenberg \& McClelland, 1989; Seidenberg, Plaut, Petersen, McClelland, \& McRae, 1994). These models abandon the assumption that words are represented by single nodes. Instead, they employ distributed representations in which a word is represented as a unique pattern of activation across a set of nodes.

One such model is the Hopfield network (Masson, 1991; see also Sharkey \& Sharkey, 1992). This model successfully accounts for a number of standard effects observed in the semantic priming literature without appealing to the notion of spreading activation (see also Borowsky $\&$ Masson, 1996; Masson, 1995). We therefore evaluate its ability to deal with nonword semantic priming here.

Concepts are represented as a pattern of activation across orthographic and semantic nodes. Each node is in either an on or off state (binary values of +1 or -1 ). The model learns concepts by associating particular orthographic patterns of activation with particular semantic patterns of activation. Identification of a printed word is simulated by first setting the entire network to a random pattern of activation. A known orthographic pattern is 
then assigned to the orthographic nodes and the semantic nodes are allowed to update. The updating procedure yields a measure of "number of cycles to settle" that is comparable to human reaction time (RT) data (see Masson, 1991, for details).

In this network, semantically related concepts are represented by setting more than $50 \%$ of their conceptual nodes in the same on or off state. This representational scheme provides a very straightforward account of semantic priming. Consider an example in which the model is presented with the orthographic pattern for DOG (the prime) and it settles on the appropriate semantic pattern for DOG. When the orthographic pattern for CAT (the target) is subsequently presented to the model, the current pattern of activation over the semantic nodes already approximates the pattern to be achieved because DOG and CAT have overlapping semantic features (four legs, fur, tail, etc.). Fewer update cycles are therefore required to move the semantic nodes to the correct target pattern relative to a baseline condition (e.g., the prime SUN followed by the target CAT). The notion of "proximity" among distributed patterns of semantically related concepts is thus an alternative to the classic notion of spreading activation among related local representations in memory.

How might this model produce a nonword priming effect? Given a pattern such as DEG, it is possible that the network will eventually produce a semantic output corresponding to the word that is most orthographically similar to the input (e.g., DOG). To conceptualize this pattern completion process, one can think of semantic memory as a three-dimensional landscape consisting of a large number of possible patterns of activation, but with known (or preferred) patterns represented as attractor basins or valleys within this landscape. These attractor basins serve as "goal states" for the output of the network. The orthographic input DEG could therefore initially produce a semantic pattern that is close to, but not resting within, an attractor basin. Over time, the network could alter this semantic pattern until it completely matches the pattern for DOG. That is, the network could settle into the nearest attractor basin or goal state.

Masson's PDP model might therefore produce a nonword priming effect when the prime is presented for a brief period of time because the updating procedure begins to change the pattern of activation across the semantic nodes so that it resembles the pattern of the subsequent target. Further, the nonword priming effect might increase in magnitude as the duration of the prime increases for the simple reason that there is more opportunity to update. There could therefore be an increased amount of overlap between the semantic pattern of the prime and the pattern of the semantically related target. Indeed, it turns out that these speculations are correct insofar as an implemented version of Masson's model produces exactly this result (see Appendix A).

To this point, we have discussed Masson's PDP model in the context of conditions in which the prime is pre- sented for either a briefer or longer duration before presentation of the target. However, this discussion neglects the distinction between prime duration and prime-target stimulus onset asynchrony (SOA). Whether the effects of activation depend on prime duration as distinct from prime-target SOA is important to pursue here because the specific influence of prime duration is fundamental to another view-a verification account.

\section{A Verification Account}

According to the activation-verification model (Becker, 1976, 1980; Paap, McDonald, Schvaneveldt, \& Noel, 1987; Paap, Newsome, McDonald, \& Schvaneveldt, 1982), the visual presentation of a letter string elicits two concurrent processes: (1) activation of lexical representations for words orthographically similar to the stimulus and (2) construction of a veridical description of the stimulus. "Recognition" relies on a verification procedure; word candidates derived from the lexical system are organized in a sensory set according to their frequency of occurrence in the language and subsequently verified against a veridical description of the stimulus.

The general idea of a verification process has attracted some attention in the literature (see Becker \& Killion, 1977; Besner, 1983, 1989; Forster, 1994; Grossberg \& Stone, 1986; Lesch \& Pollatsek, 1993; Paap \& Johansen, 1994; Van Orden, 1987). Moreover, Paap et al. (1982) made a critical assumption about the verification process that may provide a useful way to conceptualize the fate of nonword prime processing across different stimulus durations:

Because verification relies on a comparison that involves continuing perceptual analysis of the stimulus, the potential contribution of verification should be severely attenuated whenever a backward mask overwrites or erases the sensory buffer. (Paap et al., 1982, p. 574)

Consider the case in which DEG is presented to a reader. We assume that DEG will activate lexical candidates such as DOG, DIG, and DEW. When DEG is presented under conditions in which verification operates, it will reject these candidates because they do not match the veridical description of the stimulus. Paap et al. (1982) did not elaborate on the fate of lexical candidates that have been rejected, but we assume that they are no longer active in the word recognition system because a failed verification inhibits them (see Lesch \& Pollatsek, 1993, for a similar suggestion). In contrast, when DEG is presented for only a brief period, the verification process will not have enough time to function. All activated lexical candidates therefore remain active.

It is assumed that this explanation can be extended to a situation in which there is activation of semantics in such a way that an item like DEG activates the semantic representation for CAT ${ }^{5}$ More specifically, we assume that semantic activation for a particular word and its se- 
mantic neighbor is dependent on the activation of that word at the lexical level. Thus when lexical activation of that word is inhibited due to a failed match in the verification process, the supporting activation for these semantic representations no longer exists. The activation levels of these semantic representations will therefore either (1) decay back to baseline or (2) be inhibited. Once again, however, if a brief presentation precludes verification of DEG, the supporting activation for these semantic representations remains.

Thus, a verification account predicts that a nonword priming effect depends on prime duration: The effect will be manifest given a brief prime duration, but not a long prime duration.

The objectives of the present investigation were (1) to document that a nonword prime activates semantics and (2) to determine whether the time course of this priming effect can be reconciled with Paap et al.'s (1987; Paap et al., 1982) verification model or an implemented version of Masson's PDP model.

To foreshadow the results, the experiments reported here demonstrate that nonwords like DEG prime targets like CAT when DEG is presented for a brief duration and masked (Experiment 1), but not when presented for a longer duration and followed by a mask (Experiment 2). These results are inconsistent with the implemented version of Masson's PDP model, but are consistent with the verification account. Experiment 3 teases apart the contribution of prime duration and prime-target SOA by using the same prime-target SOA as in Experiment 2 (in which the priming effect was absent) and the same prime duration as in Experiment 1 (in which the priming effect was present). This experiment yields a nonword priming effect. This result is consistent with the verification account.

\section{EXPERIMENT 1}

In the experiments reported here, targets (e.g., CAT) were preceded by one of four types of primes: related and unrelated nonword primes (e.g., DEG, SEN) and related and unrelated word primes (e.g., DOG, SUN). The nonword prime conditions are of primary interest because they evaluate whether nonwords activate semantics. However, the standard word prime conditions were included for two reasons: (1) If the nonword priming effect is absent but the standard word priming effect is present, it cannot be argued that the absence of the nonword priming effect is due to subjects not processing any primes to the semantic level; and (2) if both effects are present, it is possible to determine whether nonwords weakly activate semantics. Evidence for this would come in the form of a relatedness $\times$ prime type interaction in which the word priming effect is larger than the nonword priming effect.

\section{Method}

Subjects. One hundred and thirty-two University of Waterloo students were paid for their participation in the experiment. All subjects had normal or corrected-to-normal vision.
Apparatus. Subjects viewed stimuli on a Compal monochrome monitor (Model 66200). The computer keyboard allowed subjects to control stimulus presentations and make their responses. Micro Experimental Laboratories software (Schneider, 1988, 1990) and an IBM-compatible computer controlled the stimulus displays and the timing of events and recorded the data. RTs were measured from the onset of the target on the screen to the subject's buttonpress response.

Materials and Design. The critical stimuli consisted of the 80 related-word pairs in Appendix B. Primes and targets were all five letters long. The first word of each pair was the prime and appeared in lowercase letters. The second word of each pair was the target and appeared in uppercase letters.

The 80 related-word pairs were used to form a set of four lists in such a way that each list consisted of 20 prime-target pairs in each of the following four conditions: (1) the related word prime condition (e.g., table-CHAIR), (2) the unrelated word-prime condition (e.g., order-CHAIR), (3) the related nonword-prime condition (e.g., tuble-CHAIR), and (4) the unrelated nonword-prime condition (e.g., onder-CHAIR). A nonword prime was created by replacing a letter from the second, third, or fourth position of the word primes. Word and nonword primes were rotated through the related and unrelated conditions. Nonword target trials were created by pairing a new set of 80 word primes with 80 legal nonwords (derived from words unrelated to their primes) and then altering the second, third, or fourth position of each of these primes to form legal nonwords. Each subject saw 40 word-nonword pairs and 40 nonword-nonword pairs. These pairs were rotated across subjects so that each target followed its word and nonword prime an equal number of times. The experiment began with 40 practice trials that followed the constraints outlined for the experimental trials.

Procedure. Subjects were run individually in a dimly lit, soundattenuated room. The experiment lasted approximately $15 \mathrm{~min}$. Subjects were seated in front of the keyboard and monitor and informed that two letter strings would be presented successively on each trial. Subjects were instructed to decide whether the second letter string (the target) spelled a word and to respond as quickly and accurately as possible. Subjects initiated each trial by pressing the spacebar and made word-nonword judgments by pressing the "W" and "P" keys. Left-handed subjects made word responses with the "W" key, and right-handed subjects made word responses with the "P" key.

The sequence of events for each trial was as follows: (1) A fixation cross appeared in the middle of the screen, (2) the subject pressed the spacebar to initiate the trial, (3) the prime replaced the fixation cross and remained on the screen for $40 \mathrm{msec}$, (4) a fivecharacter mask (\#\#\#\#) replaced the prime and remained on the screen for $40 \mathrm{msec}$, and (5) the target item replaced the mask and remained on the screen until response.

Under these display conditions, subjects consistently reported that they could not read the primes. They were told not to worry about this, but were told simply to ensure that they were fixating on the middle of the screen throughout each trial.

\section{Results}

Responses to word targets were faster (660 vs. $765 \mathrm{msec})$ and less error prone $(4.9 \%$ vs. $7.5 \%)$ than were responses to nonword targets $(p s<.001)$. Correct mean RTs and percentage errors for word responses in each condition were entered into a $2 \times 2$ repeated measures analysis of variance (ANOVA) with relatedness (related vs. unrelated) and prime type (word vs. nonword) as factors. ${ }^{6}$

ANOVAs were conducted on both subject and item data. For the item analyses, each subject's mean correct RT across all items was subtracted from his/her RT for 
each item. All item analyses reported here used the mean difference score for each item in each condition. We employed this procedure for the following reason: Standard item analyses involve comparisons between conditions consisting of RTs from different subjects. These comparisons confound the experimental manipulation of interest with individual differences in overall speed of response. Subtracting each subject's mean RT from his/her RT for each item partials out variability due to these individual differences. The result is an estimate of each subject's "effect size" for each item in each condition. In cases in which subject variability exceeds item variability (usually the case), this procedure enhances the power of the item analyses.

Prior to the analyses of subject and item RT data, outliers were calculated on a subject-by-subject basis for each of the four conditions using the Van Selst and Jolicoeur (1994) procedure. This is a recursive procedure with a standard deviation cutoff that varies as a function of the number of observations per condition. Van Selst and Jolicoeur have demonstrated that this procedure yields stable means across different sample sizes (the typical $S D$ cutoff in these experiments was 3.7). The procedure identified $2.9 \%$ of all correct trials as outliers, and these were removed from all RT analyses.

Inspection of Table 1 reveals that responses to targets were faster ( $24 \mathrm{msec}$ by subjects, $26 \mathrm{msec}$ by items) when preceded by related as opposed to unrelated word primes, replicating standard findings (see, e.g., Neely's 1991 review). More importantly for present purposes, target responses were also faster $(7 \mathrm{msec}$ by subjects, $9 \mathrm{msec}$ by items) when preceded by related as opposed to unrelated nonword primes.

Analyses of the RT data revealed that the main effect of prime type was not significant by subjects $\left[F_{\mathrm{s}}(1,129)=\right.$ $\left.1.5, M S_{\mathrm{e}}=1,803, p>.2\right]$, but was marginally significant by items $\left[F_{\mathrm{i}}(1,79)=2.9, M S_{\mathrm{e}}=619, p<.09\right]$. There was a main effect of relatedness $\left[F_{\mathrm{s}}(1,129)=17.2\right.$, $M S_{\mathrm{e}}=1,744, p<.001 ; F_{\mathrm{i}}(1,79)=25.8, M S_{\mathrm{e}}=881, p<$ $.001]$. The main effect of relatedness was qualified by a relatedness $\times$ prime type interaction in which the relatedness effect was significantly larger for word primes

Table 1

Mean Reaction Times (RT, in Milliseconds), Standard Errors, and Percentage Errors (\%E) for Word Targets in Experiment 1 as a Function of Relatedness and Prime Type

\begin{tabular}{|c|c|c|c|c|c|c|}
\hline & \multicolumn{6}{|c|}{ Prime Type } \\
\hline & \multicolumn{3}{|c|}{ Words } & \multicolumn{3}{|c|}{ Nonwords } \\
\hline & RT & $S E$ & $\% \mathrm{E}$ & RT & $S E$ & $\% \mathrm{E}$ \\
\hline \multicolumn{7}{|c|}{ Subjects } \\
\hline Unrelated & 670 & 4.3 & 5.9 & 666 & 4.1 & 5.0 \\
\hline Related & 646 & 4.6 & 3.4 & 659 & 3.7 & 5.3 \\
\hline Difference & 24 & & 2.5 & 7 & & -.3 \\
\hline \multicolumn{7}{|c|}{ Items } \\
\hline Unrelated & 673 & 2.9 & 5.9 & 671 & 3.0 & 5.0 \\
\hline Related & 647 & 2.7 & 3.4 & 662 & 2.6 & 5.3 \\
\hline Difference & 26 & & 2.5 & 9 & & -.3 \\
\hline
\end{tabular}

than for nonword primes $\left[F_{\mathrm{s}}(1,129)=5.9, M S_{\mathrm{e}}=1,522\right.$, $\left.p<.05 ; F_{\mathrm{i}}(1,79)=11.5, M S_{\mathrm{e}}=573, p<.01\right]$. Planned contrasts showed that the relatedness effect was significant for word primes $\left[t_{\mathrm{s}}(129)=4.2, S E_{\mathrm{d}}=5.7, p<.001\right.$, one-tailed, $t_{i}(79)=5.9, S E_{\mathrm{d}}=4.4, p<.001$, one-tailed], and significant for nonword primes $\left[t_{\mathrm{s}}(129)=1.6, S E_{\mathrm{d}}=\right.$ $4.3, p<.055$, one-tailed, $t_{\mathrm{j}}(79)=1.9, S E_{\mathrm{d}}=4.2, p<$ .04 , one-tailed].

Analyses of the error data yielded no main effect of prime type $\left[F_{\mathrm{s}}(1,129)=1.6, M S_{\mathrm{e}}=23.9, p>.20\right.$; $\left.F_{\mathrm{i}}(1,79)=2.3, M S_{\mathrm{e}}=10.6, p>.10\right]$, but a main effect of relatedness $\left[F_{\mathrm{s}}(1,129)=5.6, M S_{\mathrm{e}}=26.7, p<.05\right.$; $\left.F_{\mathrm{i}}(1,79)=4.6, M S_{\mathrm{e}}=21.8, p<.05\right]$. The main effect of relatedness was qualified by a relatedness $\times$ prime type interaction $\left[F_{\mathrm{s}}(1,129)=14.4, M S_{\mathrm{e}}=18.3, p<.001\right.$; $\left.F_{\mathrm{i}}(1,79)=8.0, M S_{\mathrm{e}}=19.6, p<.01\right]$, which revealed that the relatedness effect was reliable for word primes $\left[t_{\mathrm{s}}(129)=4.7, S E_{\mathrm{d}}=.54, p<.001\right.$, one-tailed, $t_{\mathrm{i}}(79)=$ $3.4, S E_{\mathrm{d}}=.73, p<.001$, one-tailed], but not for nonword primes $\left(t_{\mathrm{s}}<1\right)$.

\section{Discussion}

Experiment 1 yielded the standard semantic priming effect in which the presentation of a related word prime facilitated target processing. More importantly, a nonword priming effect was also observed (e.g., DEG primed CAT). From an empirical standpoint, this result suggests that Lukatela and Turvey (1994) did not employ stimulus materials that made it possible to observe semantic activation following the presentation of nonword primes. Recall that half of their primes differed from their source word by more than one letter (e.g., BLARD from BLADE). It appears that in order to observe the effects of activation that are of interest here, it is necessary to use primes that have the maximum possible degree of orthographic overlap with their source words (e.g., as in MUDIC from MUSIC).

From a theoretical standpoint, it is clear from this experiment that nonwords activate semantics sufficiently strongly to produce the effect on performance observed here. This result is consistent with Masson's PDP model and the verification model.

\section{EXPERIMENT 2}

What should happen when the nonword prime is presented for a longer duration than in Experiment 1? The verification model predicts that the nonword priming effect will be eliminated provided verification has time to operate and therefore inhibit all activated lexical candidates (because they do not match the input), which in turn causes associated semantic activation to either decay back to baseline or be inhibited. In contrast, the implemented version of Masson's PDP model (see Appendix A) produces an increase in the magnitude of the nonword priming effect because the network is given more opportunity to update. There is therefore an increased amount of overlap between the semantic pattern 
of the prime and the pattern of the semantically related target.

\section{Method}

A new group of 132 subjects was recruited for participation in this experiment. Experiment 2 was identical to Experiment 1 except that the primes were now presented for $300 \mathrm{msec}$ prior to the 40 msec mask (thus the prime-target SOA here was $340 \mathrm{msec}$ ). Subjects consistently reported that they could read the primes.

\section{Results}

Responses to word targets were faster (623 vs. $720 \mathrm{msec})$ and less error prone $(5.5 \%$ vs. $7.4 \%)$ than were responses to nonword targets $(p s<.001)$. The word target data from Experiment 2 were subjected to the same analyses as those outlined in Experiment 1. The outlier procedure resulted in $2.6 \%$ of the data being discarded.

Inspection of Table 2 reveals that responses to word targets were faster $(17 \mathrm{msec}$ by subjects, $20 \mathrm{msec}$ by items) when preceded by related as opposed to unrelated word primes. In contrast, target responses were only $2 \mathrm{msec}$ faster when preceded by related as opposed to unrelated nonword primes.

Analyses of the RT data yielded a main effect of prime type $\left[F_{\mathrm{s}}(1,131)=7.4, M S_{\mathrm{e}}=1,686, p<.01 ; F_{\mathrm{i}}(1,79)=\right.$ $\left.9.2, M S_{\mathrm{e}}=905, p<.01\right]$ and a main effect of relatedness $\left[F_{\mathrm{s}}(1,131)=7.9, M S_{\mathrm{e}}=1,625, p<.01 ; F_{\mathrm{i}}(1,79)=11.9\right.$, $\left.M S_{\mathrm{e}}=787, p<.01\right]$. These effects were qualified by a relatedness $\times$ prime type interaction $\left[F_{s}(1,131)=5.7\right.$, $M S_{\mathrm{e}}=1,424, p<.05 ; F_{\mathrm{i}}(1,79)=8.7, M S_{\mathrm{e}}=623, p<$ .01]. Planned contrasts showed that the relatedness effect was reliable for word primes $\left[t_{\mathrm{s}}(131)=3.5, S E_{\mathrm{d}}=\right.$ $5.0, p<.001$, one-tailed, $t_{\mathrm{i}}(79)=4.2, S E_{\mathrm{d}}=4.6, p<$ .001 , one-tailed], but not for nonword primes $(t \mathrm{~s}<1)$.

Analysis of the error data yielded no main effect of prime type $\left[F_{\mathrm{s}}(1,131)=1.6, M S_{\mathrm{e}}=28.9, p>.20\right.$; $\left.F_{\mathrm{i}}(1,79)=1.6, M S_{\mathrm{e}}=17.7, p>.20\right]$, but a main effect of relatedness $\left[F_{\mathrm{s}}(1,131)=14.3, M S_{\mathrm{e}}=25.1, p<.001\right.$; $\left.F_{\mathrm{i}}(1,79)=11.7, M S_{\mathrm{e}}=18.6, p<.01\right]$. The main effect of relatedness was qualified by a marginally significant relatedness $\times$ prime type interaction $\left[F_{\mathrm{s}}(1,131)=3.3\right.$, $M S_{\mathrm{e}}=26.6, p<.08 ; F_{\mathrm{i}}(1,79)=3.1, M S_{\mathrm{e}}=17.0, p<$ $.09]$, which revealed that the relatedness effect was reli-

Table 2

Mean Reaction Times (RT, in Milliseconds), Standard Errors, and Percentage Errors (\%E) for Word Targets in Experiment 2 as a Function of Relatedness and Prime Type

\begin{tabular}{|c|c|c|c|c|c|c|}
\hline & \multicolumn{6}{|c|}{ Prime Type } \\
\hline & \multicolumn{3}{|c|}{ Words } & \multicolumn{3}{|c|}{ Nonwords } \\
\hline & $\mathrm{RT}$ & $S E$ & $\% \mathrm{E}$ & $\mathrm{RT}$ & $S E$ & $\% \mathrm{E}$ \\
\hline \multicolumn{7}{|c|}{ Subjects } \\
\hline Unrelated & 627 & 4.1 & 6.5 & 629 & 3.6 & 6.2 \\
\hline Related & 609 & 3.9 & 4.0 & 627 & 3.6 & 5.4 \\
\hline Difference & 18 & & 2.5 & 2 & & .8 \\
\hline \multicolumn{7}{|c|}{ Items } \\
\hline Unrelated & 632 & 2.6 & 6.5 & 632 & 2.4 & 6.2 \\
\hline Related & 612 & 2.6 & 4.0 & 630 & 2.5 & 5.4 \\
\hline Difference & 20 & & 2.5 & 2 & & .8 \\
\hline
\end{tabular}

able for word primes $\left[t_{\mathrm{s}}(131)=4.3, S E_{\mathrm{d}}=.57, p<.001\right.$, one-tailed, $t_{\mathrm{i}}(79)=3.8, S E_{\mathrm{d}}=.64, p<.001$, one-tailed], but not for nonword primes $\left[t_{\mathrm{s}}(131)=1.2, S E_{\mathrm{d}}=.68\right.$, $p>.10$, one-tailed, $t_{\mathrm{i}}(79)=1.2, S E_{\mathrm{d}}=.69, p>.10$, one-tailed].

\section{Discussion}

The results of Experiment 2 demonstrate that, despite the standard presence of semantic priming following a word prime, no reliable priming is observed following a nonword prime. This stands in contrast to the results of Experiment 1, in which both word and nonword primes served to facilitate subsequent target processing when briefly presented.

Masson's PDP model. Given that we observed a larger nonword priming effect when the network was given the prime for a longer period of time, the model predicts that the nonword priming effect would be larger in Experiment 2 than in Experiment 1. The elimination of the nonword priming effect in Experiment 2 is thus inconsistent with this implementation of the model.

The verification model. In contrast, the results of Experiment 2 are consistent with a verification account. Lexical candidates activated by nonwords can be verified when primes are presented for a long duration prior to the mask. The nonword priming effect is eliminated because verification inhibits all activated lexical candidates (because they do not match the input). This inhibition in turn causes the semantic activation associated with these lexical candidates to decay back to baseline or be inhibited. In contrast, the observed word priming effect occurs because a lexical candidate that matches the input is not inhibited. Semantic activation associated with these candidates remains.

Rosson revisited. The absence of a nonword priming effect in Experiment 2 conflicts with the results from Rosson (1983, Experiment 1), who found a nonword priming effect with a long prime duration. However, we remind the reader that subjects in the Rosson experiment were required to name the primes out loud, and, as Rosson noted, her nonword priming effect may have been due to higher order strategies or expectancies.

\section{EXPERIMENT 3}

The results of Experiments 1 and 2 suggest that as prime duration increases, the nonword priming effect is eliminated. However, given that both prime duration and prime-target SOA increased across Experiments 1 and 2 , this conclusion is premature. That is, it is possible that the presence/absence of the nonword priming effect depends on prime-target SOA rather than prime duration.

The solution adopted here was to use the same prime duration as in Experiment 1 (a 40-msec prime followed by a mask), in which the nonword priming effect was observed, and the same prime-target SOA as in Experiment $2(340 \mathrm{msec})$, in which the nonword priming effect was eliminated. If the presence of nonword priming in 
Experiment 1 and its absence in Experiment 2 depend on prime duration, then a nonword priming effect should be observed here. On the other hand, if prime-target SOA is critical, then a nonword priming effect should not be observed here.

This experiment also provides another test of the verification account. Paap et al. (1982) argued that verification relies on subjects having a stable description of the stimulus in visual memory. More specifically, the verification procedure is inoperative when a stimulus is briefly presented and masked (making it difficult to see) but operative when presented for a longer duration (making it easy to see). In Experiment 1, the nonword priming effect was observed when primes were presented for $40 \mathrm{msec}$ and masked. It is assumed that this prime duration is sufficient for nonwords to activate semantics, but not sufficient for the verification procedure to be deployed and inhibit all activated lexical candidates (because they do not match the input). Given that we used the same prime duration in Experiment 3 as that in Experiment 1, the verification account would predict that a nonword priming effect would be observed.

\section{Method}

A new group of 132 subjects participated. The apparatus, materials, and design of Experiment 3 were identical to those of Experiments 1 and 2. However, Experiment 3 maintained the prime duration $(40 \mathrm{msec})$ used in Experiment 1 and the prime-target SOA (340 msec) used in Experiment 2. Thus, the timing of events for each trial was as follows: (1) A fixation cross appeared in the middle of the screen, (2) the subject pressed the spacebar to initiate the trial, (3) the prime replaced the fixation cross and remained on the screen for $40 \mathrm{msec}$, (4) a five-character mask (\#\#\#\#\#) replaced the prime and remained on the screen for $40 \mathrm{msec},(5)$ a 260 -msec blank field followed the mask until, ${ }^{7}(6)$ the presentation of the target. Once again, subjects consistently reported that they could not read the primes.

\section{Results and Discussion}

Responses to word targets were faster (622 vs. $720 \mathrm{msec})$ and less error prone $(4.8 \%$ vs. $6.7 \%)$ than were responses to nonword targets $(p s<.001)$. The word target data from Experiment 3 were subjected to the same analyses as those outlined in Experiments 1 and 2. The outlier procedure resulted in $3.2 \%$ of the data being discarded.

Table 3

Mean Reaction Times (RT, in Milliseconds), Standard Errors, and Percentage Errors $(\% \mathrm{E})$ for Word Targets in Experiment 3 as a Function of Relatedness and Prime Type

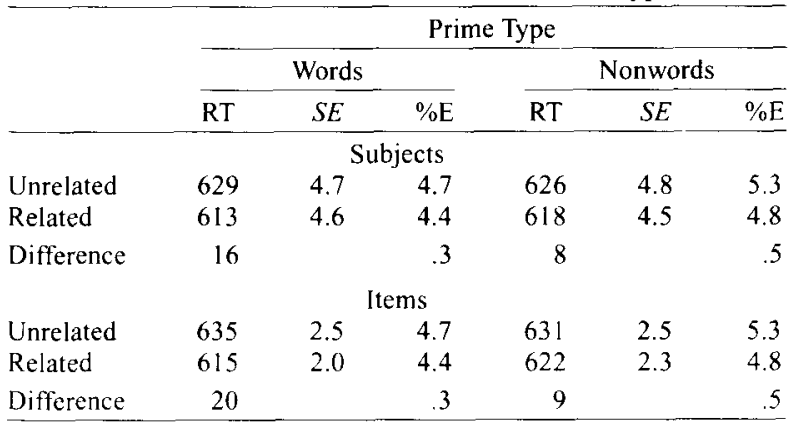

Inspection of Table 3 reveals that responses to targets were faster ( $16 \mathrm{msec}$ by subjects, $20 \mathrm{msec}$ by items) when preceded by related as opposed to unrelated word primes. Target responses were also faster $(8 \mathrm{msec}$ by subjects, 9 msec by items) when preceded by related as opposed to unrelated nonword primes.

Analyses of the RT data yielded no main effect of prime type $(F \mathrm{~S}<1)$ but did yield a main effect of relatedness $\left[F_{\mathrm{s}}(1,131)=12.0, M S_{\mathrm{e}}=1,542, p<.01 ; F_{\mathrm{i}}(1,79)=\right.$ $\left.31.2, M S_{\mathrm{e}}=431, p<.001\right]$. The relatedness $\times$ prime type interaction was not significant by subjects $\left[F_{\mathrm{s}}(1,131)=1.9, M S_{\mathrm{e}}=1,072, p>.15\right]$ and was only marginally significant by items $\left[F_{\mathrm{i}}(1,79)=3.3, M S_{\mathrm{e}}=\right.$ $423, p<.08]$. Planned contrasts showed that the relatedness effect was reliable for both word primes $\left[t_{\mathrm{s}}(131)=\right.$ $3.8, S E_{\mathrm{d}}=4.1, p<.001$, one-tailed, $t_{\mathrm{i}}(79)=4.9, S E_{\mathrm{d}}=$ $3.5, p<.001$, one-tailed $]$ and nonword primes $\left[t_{\mathrm{s}}(131)=\right.$ $1.7, S E_{\mathrm{d}}=4.7, p=.05$, one-tailed, $t_{\mathrm{i}}(79)=2.9, S E_{\mathrm{d}}=$ 3.0, $p<.01$, one-tailed].

Analyses of the error data yielded no main effects and no relatedness $\times$ prime type interaction (all $p \mathrm{~s}>.20$ ).

Experiment 3 yielded the standard semantic priming effect following a related word prime and, more importantly, also produced a nonword priming effect. Taken together with Experiments 1 and 2, this suggests that the presence of the nonword priming effect is dependent on prime duration, not prime-target SOA. This is consistent with the verification account. We return to this point in the General Discussion.

\section{Cross-Experiment Comparisons}

Further analyses were conducted in order to put our conclusions on a stronger footing.

Is the nonword priming effect due to guessing? In Experiments 1 and 3, primes were presented for only a brief duration $(40 \mathrm{msec})$. Nonetheless, it is possible that subjects attempted to guess their identity. Under these circumstances, subjects could have misread nonword primes like DEG as DOG, and this could be driving the nonword priming effect. We assume, however, that this happened on only a proportion of trials, because overall the data show that word primes produce a larger priming effect than do nonword primes. Thus, a testable prediction of this guessing account is that the variances in the related nonword condition will be larger than variances in the unrelated nonword condition. This should occur because the related condition will be based on a probability mixture of fast responses, in which the prime was seen as a word related to the subsequent target, and slow responses, in which the prime was seen as a word unrelated to the subsequent target. In contrast, the unrelated condition will consist of slow trials only, because the prime could be seen only as a word unrelated to the subsequent target. Following Fera, Jolicoeur, and Besner (1994), we computed the log (base 10) variances for these two conditions for all subjects in Experiments 1 and $3 .^{8}$ There was no evidence in either experiment that the variance in the related condition was reliably larger than the variance in the unrelated condition. In Experi- 
ment 1 , the $\log$ variances for the related and unrelated conditions were 4.10 and 4.11 , respectively $(t<1)$. In Experiment 3 , the corresponding values were 4.03 and $4.06(t<1)$. To be sure, we are not claiming that guessing never makes a contribution to performance, but only that we have no evidence that it does. ${ }^{9}$

Nonword priming as a function of prime duration. Across Experiments 2 and 3, prime duration was varied ( 300 and $40 \mathrm{msec}$, respectively), but prime--target SOA was held constant ( $340 \mathrm{msec})$. Thus, any differences in nonword priming across these two experiments can be attributed solely to prime duration. Analyses within each of these experiments revealed that nonword priming was absent at a long prime duration (Experiment 2), but present at a brief prime duration (Experiment 3 ). On the basis of these results, it has been argued that nonword priming varies with prime duration. However, this argument would be more persuasive if statistically supported across Experiments 2 and 3.

Another statistical issue also warrants consideration. Despite the fact that semantic priming with word primes is one of the most robust effects observed in the word recognition literature, there is often a considerable number of subjects who do not exhibit the effect (e.g., see Besner \& Smith, 1992). Of course, standard tests of statistical significance take this into account. Under circumstances in which an effect is significant, the distribution of values associated with the mean effect size is considered random variation. However, it is possible that subjects who fail to yield the standard semantic priming effect do not simply constitute random variation, but instead represent a distinct group of individuals who do not process prime items to the semantic level. In this case, the contribution of these individuals to the distribution of values associated with the mean effect size can be considered systematic variation.

If one accepts this premise, important consequences may arise when one now considers the nonword priming effects observed across the experiments reported here. More specifically, subjects who did not process primes to the semantic level, as indexed by those who failed to show the standard word priming effect (i.e., subjects whose mean RTs in the related word condition were equal to or larger than those in the unrelated condition), were unlikely to produce a nonword priming effect. Thus, these subjects may have been systematically contributing to an underestimate of the true size of the nonword priming effect. A stronger test of the nonword priming effect would therefore be to eliminate these subjects and focus on the data from subjects who showed a word priming effect.

Accordingly, the between-experiment comparisons reported here were conducted on two data sets: those in which data from all subjects were used (the "full" data set) and those in which data from subjects who failed to yield word priming were eliminated (the "trimmed" data set). Only analyses of the RT data are reported. The error data do not compromise any of the effects reported here.
Full data set: Experiment 2 versus 3 . The prime duration $X$ relatedness interaction with nonword primes did not reach statistical significance $\left[F_{\mathrm{s}}<1, F_{\mathrm{i}}(1,79)=\right.$ $\left.1.6, M S_{\mathrm{e}}=458, p>.20\right]$. This null result is not surprising given (1) the small magnitude of the difference in the nonword priming effects across Experiments 2 and 3 ( $2 \mathrm{msec}$ in Experiment 2 vs. $9 \mathrm{msec}$ in Experiment 3 ) and (2) the lack of statistical power associated with cross-experiment comparisons.

Trimmed data set: Experiment 2 versus 3.10 The nonword priming effect in Experiment 2 remained at $2 \mathrm{msec}$ $\left[t_{\mathrm{s}}(85)<1 ; t_{\mathrm{i}}(79)<1\right]$ but increased in magnitude in Experiment 3 to $17 \mathrm{msec}\left[t_{\mathrm{s}}(80)=3.1, S E_{\mathrm{d}}=5.8, p<.005\right.$; $\left.t_{\mathrm{i}}(79)=3.7, S E_{\mathrm{d}}=4.7, p<.001\right]$. More importantly, the prime duration $\times$ relatedness interaction revealed these nonword priming effects to be significantly different $\left[F_{\mathrm{s}}(1,165)=4.0, M S_{\mathrm{e}}=1,348, p<.05 ; F_{\mathrm{i}}(1,79)=6.2\right.$, $\left.M S_{\mathrm{e}}=759, p<.05\right]$. This analysis supports the idea that nonword priming varies as a function of prime duration. Nonword priming is present when primes are presented for a brief duration ( $40 \mathrm{msec}$ in Experiment 3 ) but not when presented for a longer duration $(300 \mathrm{msec}$ in Experiment 2).

One final point is worth emphasizing. The results from the trimmed data from Experiment 2 rule out the argument that there was in fact a nonword priming effect present in the full data set of Experiment 2 that was simply being masked by subjects who did not process any primes to the semantic level. Even when one examines the data only from subjects who appear to have been processing primes to the semantic level (i.e., those subjects who showed a word priming effect), there is no hint of a nonword priming effect. Thus it is reasonable to conclude that nonword priming is not manifest at a long prime duration. This point is supported further by the fact that the trimmed data set for Experiment 2 had an acceptable level of statistical power (.78 by subjects, .86 by items) to detect a nonword priming effect of the size found in the trimmed data sets for Experiments 1 and 3 . In other words, one can conclude that the true effect size in Experiment 2, if one exists, is probably smaller than that found in Experiments 1 and 3.

Nonword priming effect as a function of primetarget SOA. Across Experiments 1 and 3, prime-target SOA was varied ( 80 and $340 \mathrm{msec}$, respectively), but prime duration was held constant $(40 \mathrm{msec})$. Thus, any differences in nonword priming across these two experiments can be attributed solely to prime-target SOA. Analysis of the full and trimmed data sets ${ }^{11}$ revealed that the nonword priming effect did not vary as a function of prime-target SOA [full data set: $F_{\mathrm{s}}$ and $F_{\mathrm{i}}<1$; trimmed data set: $\left.F_{\mathrm{s}}<1, F_{\mathrm{i}}(1,79)=1.33, M S_{\mathrm{e}}=831, p>.25\right]$. As in Experiment 3, the nonword priming effect in the trimmed data set of Experiment $1(10 \mathrm{msec})$ was significant $\left[t_{\mathrm{s}}(93)=1.9, S E_{\mathrm{d}}=5.4, p<.07 ; t_{\mathrm{i}}(79)=2.1, S E_{\mathrm{d}}=\right.$ $4.7, p<.05]$.

To summarize, analyses of the trimmed data sets from these experiments show that nonword priming varies as 
a function of prime duration (nonword priming was present at a 40-msec prime duration, but absent at a 300msec prime duration), but not as a function of prime-target SOA (nonwords presented for $40 \mathrm{msec}$ produced an equivalent amount of priming at prime-target SOAs of 80 and $340 \mathrm{msec}$ ).

Word priming effect as a function of prime duration and/or prime-target SOA. A further question addressed briefly was whether word priming varied in magnitude across the experiments reported here. Previous investigations using display parameters similar to those used here have reported that word priming increases as (1) prime duration increases (Balota, 1983) and (2) prime duration and prime-target SOA increase together (de Groot, Thomassen, \& Hudson, 1986). The finding that word priming increases as subjects are given more time to process the prime items is consistent with both of the models described here. The verification account appeals to the notion of spreading activation (Collins \& Loftus, 1975; Collins \& Quillian, 1969), in which degree of activation of semantic concepts in memory increases (at least initially) with processing time. Masson's PDP model also accommodates this finding because when the network is given more time for pattern completion, there will be an increased amount of overlap between the semantic pattern of the prime and the pattern of the semantically related target (see Appendix B).

Neither prime duration (Experiment 2 vs. 3) nor concurrent manipulation of prime duration and primetarget SOA (Experiment 1 vs. 2) affected the magnitude of the word priming effect in our experiments (all $p s>$ .25 ). The absence of these effects is puzzling, but may just be a Type II error.

\section{GENERAL DISCUSSION}

The results of these three experiments can be summarized as follows. The standard semantic priming effect, in which word primes facilitate target processing, was observed in all three experiments. In contrast, the nonword priming effect, in which nonword primes facilitate the processing of a semantically related target, was dependent on the duration of the prime. When nonword primes were briefly presented and masked, priming of related targets was observed regardless of whether the prime-target SOA was short $(80 \mathrm{msec}$ in Experiment 1) or long ( $340 \mathrm{msec}$ in Experiment 3 ). In contrast, no priming was observed when a nonword prime was presented for a sufficiently long duration (300 $\mathrm{msec}$ in Experiment 2) that subjects reported seeing it. It thus appears that some process associated with a longer duration prime served to eliminate the initial semantic activation.

\section{The Verification Account}

The fact that prime duration determined whether or not a nonword priming effect was observed in these experiments is consistent with the verification account.
Nonword primes activate lexical representations of orthographically similar words. This activation cascades further, activating semantic representations for these and related words. When the prime is presented for a long duration, the activated lexical candidates are verified against the visual representation of the stimulus, and no match is found. Consequently, these lexical candidates are deactivated, and the semantic activation generated by these candidates decays back to baseline or is inhibited. There will therefore be no nonword semantic priming. Following Paap et al. (1982), we assume that when the nonword prime is presented for a brief duration and masked, the verification mechanism does not have enough time to function. Consequently, all activated lexical and/or semantic candidates remain active. A nonword semantic priming effect is therefore observed.

\section{A Rapprochement With Masson's PDP Model}

Simulations using Joordens and Besner's (1994) implemented version of this model showed that the nonword priming effect becomes larger as the duration of the prime increases. In contrast, Experiment 2 showed that the nonword priming effect was eliminated with a longer prime duration. The simulation data are understandable in terms of the model's pattern completion abilities, but there is clearly something awry. It is possible to modify this model in two different ways to accommodate these results.

Deconstructing semantic activation. Masson and Borowsky (1995) and Borowsky and Masson (1996) have demonstrated that a Hopfield network can make lexical decisions by using a procedure that monitors the "goodness of fit between the current states of the processing units and the connection weights that link them" (Masson \& Borowsky, 1995, p. 512). Words provide better fits than do nonwords, and this forms the basis of the lexical decision. It is thus plausible to think of goodness of fit (also known as "energy" or "harmony") as a means by which the model can "verify" an item as a word (good fit) or not (poor fit). If it is further assumed that (1) this verification is successful only when primes are presented for a long duration (i.e., "visible"), and (2) verifying an item as a nonword drives (or deconstructs) all semantic activity back down to baseline, one is left with a view that is similar in principle to Paap's (Paap et al., 1982). Such an idea is also very similar to that incorporated in adaptive resonance networks (e.g., Grossberg \& Stone, 1986; Stone \& Van Orden, 1994), in which activation of higher level representations is continuously modified on the basis of lower level input.

A stringent updating procedure. Another possibility is that semantic activation produced by a nonword prime is more directly linked to semantic activation arising from orthographic activation under the two prime duration conditions. More specifically, we wish to consider the possibility that a brief prime duration allows the orthographic units to send a weak but sufficiently coherent 
pattern of activation to semantics (so that nonword priming is observed), whereas a longer prime duration allows the orthographic units to send a stronger but incoherent pattern of activation to semantics (so that nonword priming is not observed).

This view depends on the assumption that the representation of a nonword prime in the model's orthographic units differs under brief versus long display conditions. One could imagine that a full orthographic representation (in which every unit takes on either a +1 or -1 value) of a nonword prime may not be possible when the prime is presented for a brief duration and masked. Nonetheless, a partial pattern of \pm 1 values (e.g., across half of the orthographic units) may be sufficient to activate semantics.

Consider now, however, the condition in which the nonword prime has been presented for a longer duration, so that it provides ample time for the full pattern to be represented across the orthographic units. If, rather than gradually moving the network to the semantic basin of an orthographically similar word, the orthographic units now capture enough of the nonword letter string's pattern to distinguish it from real words, semantic activation may simply fail to develop. One way to adapt the model to accomplish this type of discrimination process would be to make the updating procedure for semantics considerably more stringent, so that a change in the state of any given semantic unit is more heavily determined by the presence of a coherent signal from the orthographic units. In the absence of a coherent signal-as in the case of a well-specified nonword prime - semantic units remain in a "suspended" random state corresponding to a pattern unknown to the model (see also Rueckl, 1995, and Plaut et al., 1996, for a discussion of the notion of sparse semantic representations in other connectionist models).

In summary, we offer this account as an alternative way to conceptualize the absence of nonword priming at a long prime duration. This view emphasizes that rather than "deconstructing" semantic activation generated by the earlier processing of a nonword, the long prime duration provides the conditions under which semantic activation does not accrue in the first place.

To put it another way, it is important to keep in mind that the outcome of a simulation may speak more to the implementation of the model than to the model's principles. A model may thus fail to adequately describe human data because of some defect in the implementation. Our intuition is that the current coding scheme in both Masson's (1991) and Joordens and Besner's (1994) implementations are simply too crude to provide an accurate account of the nonword priming effect documented here.

\section{Summary and Conclusions}

The experiments reported here demonstrate that nonwords activate semantics. Further, the semantic activa- tion generated by these nonwords depends on their presentation duration; semantic priming is present when nonwords are briefly presented and masked, but absent when they are presented for a longer period prior to the mask. Any comprehensive account of "priming" in visual word recognition will need to accommodate these findings.

\section{REFERENCES}

Balota, D. A. (1983). Automatic semantic activation and episodic memory encoding. Journal of Verbal Learning \& Verbal Behavior, 22, 88-104.

BECKER, C. A. (1976), Allocation of attention during visual word recognition. Journal of Experimental Psychology: Human Perception \& Performance, 2. 556-566.

BECKER, C. A. (1980). Semantic context effects in visual word recognition: An analysis of semantic strategies. Memory \& Cognition, 8 , 493-512.

BECKER, C. A., \& KiLLION, T. H. (1977). Interaction of visual and cognitive effects in word recognition. Journal of Experimental Psychology: Human Perception \& Performance, 3, 389-401.

BESNER, D. (1983). Basic decoding components in reading: Two dissociable feature extraction processes. Canadian Journal of Psychology, 38, 429-438.

BESNER, D. (1989). On the role of outline shape and word-specific visual pattern in the identification of function words: NONE. Quarterly Journal of Experimental Psychology, 41 A, 91-105.

Besner, D., Dennis, I., \& Davelaar, E. (1985). Reading without phonology? Quarterly Journal of Experimental Psychology, 37A, 477-492.

BESNER, D., \& SMITH, M. C. (1992). Models of visual word recognition When obscuring the stimulus yields a clearer view. Journal of Experimental Psychology: Learning, Memory, \& Cognition, 18, 468-482.

BoRoWsKy, R., \& MASSON, M. E. J. (1996). Semantic ambiguity effects in word identification. Journal of Experimental Psychology: Learning, Memory, \& Cognition, 22, 63-85.

Collins, A. M., \& Loftus, E. F. (1975). A spreading activation theory of semantic processing. Psychological Review, 82, 407-428.

Collins, A. M., \& Quillian, M. R. (1969). Retrieval time from semantic memory. Journal of Verbal Learning \& Verbal Behavior, 8 , 240-248.

de Groot, A. M. B., Thomassen, A. J. W. M., \& Hudson, P. T. W. (1986). Primed-lexical decision: The effect of varying the stimulusonset asynchrony of prime and target. Acta Psychologica, 61, 17-36.

EvetT, L. J., \& Humphreys, G. W. (1981). The use of abstract graphemic information in lexical access. Quarterly Journal of Experimental Psychology, 33, 325-350.

Fera, P., Jolicoeur, P., \& Besner, D. (1994). Evidence against early selection: Stimulus quality effects in previewed displays. Journal of Experimental Psychology: Human Perception \& Performance, 20. 259-275.

Ferrand, L., \& Grainger, J. (1992). Phonology and orthography in visual word recognition: Evidence from masked non-word priming. Quarterly Journal of Experimental Psychology, 45A, 353-372.

FoRSTER, K. I. (1992, November). Lexical effects in masked formpriming. Paper presented at the thirty-third annual meeting of the Psychonomic Society, St. Louis.

Forster, K. I. (1994). Computational modeling and elementary process analysis in visual word recognition. Journal of Experimental Psychology: Human Perception \& Performance, 20, 1292-1310.

Forster, K. I., Davis, C., Schoknecht, C., \& Carter, R. (1987). Masked priming with graphemically related forms: Repetition or partial activation? Quarterly Journal of Experimental Psychology, 39A, 211-251.

GrossberG, S., \& Stone, G. (1986). Neural dynamics of word recognition and recall: Attentional priming, learning, and resonance. $P_{S y}$ chological Review, 93, 46-74. 
Hinton, G. E., \& Shallice, T. (1991). Lesioning an attractor network: Investigations of acquired dyslexia. Psychological Review, 98, 74-95.

Humphreys, G. W., Evett, L. J., \& Quinlan, P. T. (1990). Orthographic processing in visual word identification. Cognitive Psychology, 22, 517-560.

JoORDENS, S., \& BESNER, D. (1994). When banking on meaning is not yet money in the bank: Explorations in connectionist modeling. Journal of Experimental Psychology: Learning. Memory, \& Cognition, 20, 105 1-1062.

Lesch, M. F., \& PollatseK, A. (1993). Automatic access of semantic information by phonological codes in visual word recognition. Journal of Experimental Psychology: Learning, Memory, \& Cognition, 19, 285-294.

Lukatela, G., \& Turvey, M. T. (1991). Phonological access of the lexicon: Evidence from associative priming with pseudohomophones. Journal of Experimental Psychology: Human Perception \& Performance, 17, 951-966.

Lukatela, G., \& Turvey, M. T. (1993). Similar attentional, frequency, and associative effects for pseudohomophones and words. Journal of Experimental Psychology: Human Perception \& Performance, 19 166-178.

LuKatela, G., \& Turvey, M. T. (1994). Visual lexical access is initially phonological: 1 . Evidence from associative priming by words homophones, and pseudohomophones. Journal of Experimental Psychology: General, 123, 107-128.

MAsSON, M. E. J. (1991). A distributed memory model of context effects in word identification. In D. Besner \& G. W. Humphreys (Eds.), Basic processes in reading: Visual word recognition (pp. 233-263). Hillsdale, NJ: Erlbaum.

Masson, M. E. J. (1995). A distributed memory model of semantic priming. Journal of Experimental Psychology: Learning, Memory, \& Cognition, 21, 3-23.

Masson, M. E. J., \& BorowsKy, R. (1995). Unsettling questions about semantic ambiguity in connectionist models: Comment on Joordens and Besner. Journal of Experimental Psychology: Learning, Memory, \& Cognition, 21, 509-514.

MCClelland, J. L. (1987). The case for interactionism in language processing. In M. Coltheart (Ed.), Attention and performance XII: The psychology of reading (pp. 3-35). Hillsdale, $\mathrm{NJ}$ : Erlbaum.

McClelland, J. L., \& Rumelhart, D. E. (1981). An interactive activation model of context effects in letter perception: Part 1. An account of basic findings. Psychological Review, 88, 375-407.

MORTON, J. (1969). Interaction of information in word recognition. Psychological Review, 76, 165-178.

NeELy, J. H. (1991). Semantic priming effects in visual word recognition: A selective review of current findings and theories. In D. Besner \& G. Humphreys (Eds.), Basic processes in reading: Visual word recognition (pp. 264-336). Hillsdale, NJ: Erlbaum.

PaAP, K. R., \& Johansen, L. S. (1994). The case of the vanishing frequency effect: A retest of the verification model. Journal of Experimental Psychology: Human Perception \& Performance, 20, $1129-1157$

PaAP, K. R., McDonald, J. E., Schvaneveldt, R. W., \& Noel, R. W. (1987). Frequency and pronounceability in visually presented naming and lexical decision tasks. In M. Coltheart (Ed.), Attention and performance XII: The psychology of reading (pp. 221-243). Hillsdale, NJ: Erlbaum.

Paap, K. R., Newsome, S. L., McDonald, J. E., \& Schvaneveldt, R. W. (1982). An activation-verification model for letter word recognition: The word-superiority effect. Psychological Review, 89, 573-594.

Plaut, D. C., McClelland, J. L., Seidenberg, M. S., \& Patterson, K. E. (1996). Understanding normal and impaired word reading: Computational principles in quasi-regular domains. Psychological Review, 103, 56-115.

Plaut, D. C., \& Shallice, T. (1993). Deep dyslexia: A case study of connectionist neuropsychology. Cognitive Neuropsychology, 10, 377500 .

Quillian, M. R. (1968). Semantic memory. In M. Minsky (Ed.), Semantic information processing (pp. 216-270). Cambridge, MA: MIT Press.
RATCLIFF, R., \& MCKoON, G. (1988). A retrieval theory of priming in memory. Psychological Review, 95, 385-408.

Rosson, M. B. (1983). From SOFA to LOUCH: Lexical contributions to pseudoword pronunciation. Memory \& Cognition, 11, 152-160.

RUECKL, J. G. (1995). Ambiguity and connectionist networks: Still settling into a solution-Comment on Joordens and Besner (1994). Journal of Experimental Psychology: Learning, Memory, \& Cognition, 21, 501-508.

Rumelhart, D. E., McClelland, J. L., \& The PDP Research Group (1986). Parallel distributed processing: Explorations in the microstructures of cognition. Vol. 1: Foundations. Cambridge, MA: MIT Press.

SCHNEIDER, W. (1988). Micro Experimental Laboratory: An integrated system for IBM PC compatibles. Behavior Research Methods, Instrumentation, \& Computers, 20, 206-217.

SCHNEIDER, W. (1990). Mel user's guide: Computer techniques for real time experimentation. Pittsburgh: Psychology Software Tools.

Seidenberg, M. S., \& MCClelland, J. L. (1989). A distributed, developmental model of word recognition and naming. Psychological Review, 96, 523-568.

Seidenberg, M. S., Plaut, D. C., Petersen, A. S., McClelland, J. L., \& McRAE, K. (1994). Nonword pronunciation and models of word recognition. Journal of Experimental Psychology: Human Perception \& Performance, 20, 1177-1196.

SharkeY, A. J. C., \& Sharkey, N. E. (1992). Weak contextual constraints in text and word priming. Journal of Memory \& Language, 31, 543-572.

Stolz, J. A., \& Besner, D. (1996). The role of set in visual word recognition: Activation and activation blocking as non-automatic processes. Journal of Experimental Psychology: Human Perception \& Performance, 22, 1166-1177.

STONE, G. O., \& VAN ORden, G. C. (1994). Building a resonance framework for word recognition using design and system principles. Journal of Experimental Psychology: Human Perception \& Performance, 20, 1248-1268.

TAFT, M. (1991). Reading and the mental lexicon. Hove, U.K.: Erlbaum.

VAN ORDEN, G. C. (1987). A ROWS is a ROSE: Spelling, sound, and reading. Memory \& Cognition, 15, 181-198.

VAN Selst, M., \& Jolicoeur, P. (1994). A solution to the effect of sample size on outlier elimination. Quarterly Journal of Experimental Psychology, 47A, 631-650.

\section{NOTES}

1. Given that the interactive activation (IA) framework is discussed in the introduction, some readers might wonder whether the IA model produces semantic priming following the presentation of a nonword. It suffices to note that, in its present form, the model has received little attention in the context of semantic priming (but see Stolz \& Besner, 1996). Indeed, some authors have gone so far as to argue that semantic priming is not possibie in the context of the IA model (Taft, 1991).

2. For ease of exposition, we discuss the nonword priming effects observed here in terms of semantic activation via orthography, although it is certainly possible that phonology is playing a role.

3. Rosson (1983, Experiment 2) also examined semantic priming for nonword targets (i.e., SHEEP as a prime for FAMB), and the results were inconclusive. We do not consider this paradigm as an effective test of the hypothesis that nonwords activate semantics, for the following reason: Even if it were the case that SHEEP primes FAMB, such an effect could be due to letter-level priming. That is, SHEEP activates LAMB at the semantic level, which feeds activation back to letter-level representations for $\mathrm{A}, \mathrm{M}$, and $\mathrm{B}$, thus facilitating the processing of FAMB.

4 . It is an interesting question as to whether words that are orthographically similar to words related to a target will produce priming (e.g., will DIG prime CAT?). The only data we are aware of that speak to this issue are Lesch and Pollatsek's (1993) null findings (BENCH does not prime NUT).

5. Early verification accounts (e.g., Becker, 1980) assumed that semantic priming is produced by the conscious generation (from the 
prime) of a semantically defined set rather than by spreading activation. However, Paap's (personal communication, 1994) verification account includes the idea that semantic representations are activated in the absence of a conscious expectancy.

6. Across all experiments reported here, subjects producing either a mean RT over $1,000 \mathrm{msec}$ or an error rate in excess of $40 \%$ in any one condition were removed from the analyses. These criteria resulted in the data from 2 subjects being removed from Experiment 1 .

7. Unlike the masks in Experiments 1 and 2, the mask in Experiment 3 was not temporally abutted to the target. However, we are aware of no literature that would suggest that this methodological deviation would invalidate the comparison of Experiment 3 with Experiments 1 and 2.

8. This transformation ensures that the variances are normally distributed.

9. We have interpreted the nonword priming effect in the context of a prospective account. That is, DEG primes CAT because DEG activates semantic-level representations for CAT via DOG. However, another account is that subjects actively use target items to retrospectively interpret prime items. Thus, the target CAT is used as a cue to interpret DEG as DOG. Borrowing from compound-cue theory (Ratcliff \& McKoon, 1988), it might then be assumed that DOG and CAT form a highly familiar compound cue, which in turn facilitates the lexical decision response. However, one problem with this account is that it would seem to predict that increasing prime duration would afford subjects a greater opportunity to interpret nonword primes in order to construct the compound cue for a response, and thus should lead to an increased nonword priming effect. The experiments reported here show that increasing prime duration eliminates the nonword priming effect.

10. The trimming procedure resulted in 46 subjects out of 132 being removed from Experiment 2 and 51 out of 132 from Experiment 3. These proportions are very similar to the proportion of subjects who did not show a semantic priming effect in Besner and Smith's (1992) naming experiment.

11. The trimming procedure resulted in 36 subjects out of 130 being removed from Experiment 1.

\section{APPENDIX A \\ Word and Nonword Priming in the Joordens and Besner (1994) Hopfield Network: A Simulation}

\section{Method}

The current simulations were conducted in a manner similar to those by Joordens and Besner (1994) and Masson (1991). Specifically, the network architecture consisted of 75 orthographic and 50 semantic nodes. The learning algorithm was a simple Hebbian algorithm that is sensitive to correlations between the on/off states of nodes across the learned patterns when sampled in a pairwise fashion. Finally, the algorithm controlling the settling of the network is an asynchronous updating algorithm that alters the state of a sampled node on the basis of the summed input to that node from the rest of the nodes in the network. Given these characteristics, the present simulations were performed in the following manner.

On each pass the network first learned four concepts: (1) a randomly generated Target 1 ; (2) Prime 1 forced to have 38 of 50 semantic nodes in the same on or off state as Target 1 ; (3) a randomly generated Target 2; (4) Prime 2 forced to have 38 of 50 semantic nodes in the same state as Target 2 . Note also that Prime 1 had only 25 of 50 semantic nodes in the same state as Target 2, and Prime 2 had the same overlap with Target 1.

Simulation of word priming. The network retrieved Target 1 after first processing either Prime 1 (a related prime) or Prime 2 (an unrelated prime). Then Target 2 was retrieved similarly after Prime 2 (a related prime) or Prime 1 (an unrelated prime).

Simulation of nonword priming. This condition used the same learned concepts and procedures as those outlined above. However, in order to simulate nonword priming, the orthographic patterns for Primes 1 and 2 were altered so that they had a $75 \%$ to $80 \%$ overlap with their learned orthographic patterns. In other words, the target CHAIR was now preceded by TAGLE as opposed to TABLE (related condition), or ORGER as opposed to ORDER (unrelated condition).

Simulation of prime duration and masking. Primes were presented for four different numbers of processing cycles: 50 , 100,150 , or 200 cycles. This manipulation was considered analogous to a manipulation of prime duration. In order to simulate the masking procedures used in the experiments reported here, a random pattern was fed to the orthographic nodes for 40 cycles after the offset of a prime. An important question is whether this random pattern would drive the semantic nodes toward a random state, thereby precluding the possibility of a semantic priming effect. Masson (1995, p. 8) provided an answer:

If the intervening item [between a prime and target] is a neutral stimulus with no linguistic relevance (e.g., a row of $x \mathrm{~s}$ ), the orthographic module is assumed to take on a random pattern of activation (one not previously learned by the system) and will therefore not have a systematic influence on the pattern of activation in the meaning [semantic] ... modules .... The pattern of activation in the meaning ... modules will move closer to the stable state that corresponds to the prime, thereby establishing a robust priming effect on the upcoming target.

Each pass consisted of 32 retrievals, 16 of Target 1 and 16 of Target 2. Each target was subjected to a 2 (relatedness) $\times 2$ (prime lexicality) $\times 4$ (prime duration) factorial manipulation. There were 5,000 independent passes, each with four new concepts. This resulted in a total of 160,000 observations, 5,000 per condition (collapsing across targets within each pass).

\section{Results and Discussion}

The results of the simulation appear in Table Al. The dependent measure was the number of cycles to settle on the target's conceptual representation (i.e., target retrieval time). (The proportion of errors produced by the model was negligible, ranging from .001 to .06 . It suffices to say that analyses of the error data yielded results comparable to those observed in the cycles to settle data.) These data were analyzed in a 2 (relatedness) $\times 2$ (prime type) $\times 4$ (prime duration) repeated measures

Table A1

Mean Number of Cycles to Settle for Word Targets in the Hopfield Network Simulation as a Function of Relatedness, Prime Type, and Prime Duration

\begin{tabular}{|c|c|c|c|c|c|c|c|c|}
\hline & \multicolumn{8}{|c|}{ Prime Duration } \\
\hline & \multicolumn{2}{|c|}{50 Cycles } & \multicolumn{2}{|c|}{100 Cycles } & \multicolumn{2}{|c|}{150 Cycles } & \multicolumn{2}{|c|}{200 Cycles } \\
\hline & Word & Nonword & Word & Nonword & Word & Nonword & Word & Nonword \\
\hline Unrelated & 197 & 195 & 203 & 200 & 204 & 202 & 205 & 201 \\
\hline Related & 163 & 166 & 158 & 161 & 157 & 160 & 157 & 160 \\
\hline Difference & 34 & 29 & 45 & 39 & 47 & 42 & 48 & 41 \\
\hline
\end{tabular}


ANOVA (with each independent pass considered a "subject"). (There were 106 passes in which both target retrievals for at least one experimental condition were incorrect, thus precluding the possibility of calculating a mean correct RT for the[se] condition[s]. These passes were therefore removed from the analysis, leaving 4,894 passes [or "subjects"] in the analysis.) There was a main effect of relatedness $[F(1,4893)=9,363.01$, $p<.001]$, which was qualified by a relatedness $\times$ prime type interaction $[F(1,4893)=65.64, p<.001]$ and a relatedness $\times$ prime duration interaction $[F(3,14679)=80.12, p<.001]$. These interactions indicated that the relatedness effect for word primes was larger than that for nonword primes, and that the relatedness effects increased with longer prime durations. All other effects were nonsignificant (all $p \mathrm{~s}<.20$ ). The critical results from these analyses are that the network produced a nonword priming effect, and that this effect increased with longer prime durations. This is exactly what was predicted on the basis of the pattern completion abilities of the network.

APPENDIX B

The Critical Stimuli for Experiments 1, 2, and 3

\begin{tabular}{|c|c|c|c|c|c|}
\hline & $\begin{array}{c}\text { Related } \\
\text { Word } \\
\text { Prime }\end{array}$ & $\begin{array}{c}\text { Unrelated } \\
\text { Word } \\
\text { Prime }\end{array}$ & $\begin{array}{l}\text { Related } \\
\text { Nonword } \\
\text { Prime }\end{array}$ & $\begin{array}{l}\text { Unrelated } \\
\text { Nonword } \\
\text { Prime } \\
\end{array}$ & Target \\
\hline 1 & given & house & gilen & houge & TAKEN \\
\hline 2 & spray & given & sproy & gilen & PAINT \\
\hline 3 & shoes & spray & spoes & sproy & SOCKS \\
\hline 4 & angel & shoes & antel & spoes & DEVIL \\
\hline 5 & needs & angel & neeks & antel & WANTS \\
\hline 6 & river & needs & ruver & neeks & CREEK \\
\hline 7 & fleas & river & fluas & ruver & TICKS \\
\hline 8 & corks & fleas & corms & fluas & WINES \\
\hline 9 & tight & corks & teght & corms & LOOSE \\
\hline 10 & ideas & tight & idoas & teght & PLANS \\
\hline 11 & slide & ideas & slike & idoas & RULER \\
\hline 12 & cloud & slide & choud & slike & SKIES \\
\hline 13 & polka & cloud & ponka & choud & WALTZ \\
\hline 14 & jails & polka & jaips & ponka & CELLS \\
\hline 15 & grass & jails & gnass & jaips & WEEDS \\
\hline 16 & royal & grass & ropal & gnass & KINGS \\
\hline 17 & point & royal & poilt & ropal & SHARP \\
\hline 18 & sneer & point & skeer & poilt & LAUGH \\
\hline 19 & wagon & sneer & wafon & skeer & WHEEL \\
\hline 20 & house & wagon & houge & wafon & BRICK \\
\hline 21 & teach & teeth & toach & telth & LEARN \\
\hline 22 & lifts & teach & lirts & toach & DROPS \\
\hline 23 & sleep & lifts & slemp & lirts & WAKES \\
\hline 24 & speak & sleep & skeak & slemp & SPOKE \\
\hline 25 & plant & speak & plint & skeak & SEEDS \\
\hline 26 & fairy & plant & faimy & plint & TALES \\
\hline 27 & coral & fairy & cural & faimy & REEFS \\
\hline 28 & metal & coral & megal & cural & SHINY \\
\hline 29 & carry & metal & cargy & megal & BRING \\
\hline 30 & sells & carry & salls & cargy & GOODS \\
\hline 31 & study & sells & stady & salls & BOOKS \\
\hline 32 & awake & study & awane & stady & DREAM \\
\hline 33 & coins & awake & clins & awane & MONEY \\
\hline 34 & pearl & coins & peerl & clins & JEWEL \\
\hline 35 & north & pearl & norgh & peerl & SOUTH \\
\hline 36 & spice & north & skice & norgh & HERBS \\
\hline 37 & board & spice & boird & skice & PLANK \\
\hline 38 & train & board & traln & boird & TRACK \\
\hline 39 & lower & train & liwer & traln & RAISE \\
\hline 40 & teeth & lower & telth & liwer & MOUTH \\
\hline 41 & plays & angry & pluys & angdy & GAMES \\
\hline 42 & loves & plays & lovos & pluys & HATES \\
\hline 43 & tells & loves & tulls & lovos & TALKS \\
\hline 44 & salty & tells & safty & tulls & SWEET \\
\hline 45 & fraud & salty & frald & safty & CHEAT \\
\hline 46 & whole & fraud & wiole & frald & PARTS \\
\hline 47 & chair & whole & chuir & wiole & TABLE \\
\hline 48 & mount & chair & moult & chuir & HORSE \\
\hline
\end{tabular}


APPENDIX B (Continued)

\begin{tabular}{|c|c|c|c|c|c|}
\hline & $\begin{array}{c}\text { Related } \\
\text { Word } \\
\text { Prime }\end{array}$ & $\begin{array}{c}\text { Unrelated } \\
\text { Word } \\
\text { Prime } \\
\end{array}$ & $\begin{array}{c}\text { Related } \\
\text { Nonword } \\
\text { Prime } \\
\end{array}$ & $\begin{array}{l}\text { Unrelated } \\
\text { Nonword } \\
\text { Prime } \\
\end{array}$ & Target \\
\hline 49 & meats & mount & miats & moult & STEAK \\
\hline 50 & maybe & magic & marbe & magoc & MIGHT \\
\hline 51 & magic & maybe & magoc & marbe & TRICK \\
\hline 52 & songs & meats & sengs & miats & POEMS \\
\hline 53 & child & songs & cheld & sengs & YOUNG \\
\hline 54 & thief & child & thirf & cheld & CROOK \\
\hline 55 & bible & thief & beble & thirf & STORY \\
\hline 56 & barns & bible & balns & beble & SHEDS \\
\hline 57 & girls & barns & girns & balns & WOMEN \\
\hline 58 & hills & girls & holls & girns & BUMPS \\
\hline 59 & value & hills & vanue & holls & WORTH \\
\hline 60 & angry & value & angdy & vanue & UPSET \\
\hline 61 & bread & usher & breld & uther & WATER \\
\hline 62 & bathe & bread & buthe & breld & NAKED \\
\hline 63 & march & bathe & manch & buthe & APRIL \\
\hline 64 & major & march & majar & manch & MINOR \\
\hline 65 & rigid & major & rogid & majar & STIFF \\
\hline 66 & globe & rigid & glibe & rogid & WORLD \\
\hline 67 & stems & globe & stefs & glibe & TWIGS \\
\hline 68 & monks & stems & manks & stefs & ROBES \\
\hline 69 & pants & monks & palts & manks & SHIRT \\
\hline 70 & ocean & pants & oceln & palts & WAVES \\
\hline 71 & coats & ocean & clats & oceln & VESTS \\
\hline 72 & heads & green & hends & grenn & TAILS \\
\hline 73 & green & heads & grenn & hends & OLIVE \\
\hline 74 & sober & coats & siber & clats & DRUNK \\
\hline 75 & flesh & sober & flosh & siber & BLOOD \\
\hline 76 & fatal & flesh & fatil & flosh & DEATH \\
\hline 77 & lakes & fatal & lokes & fatil & PONDS \\
\hline 78 & faces & lakes & fapes & lokes & CROWD \\
\hline 79 & bolts & faces & bolps & fapes & SCREW \\
\hline 80 & usher & bolts & uther & bolps & MOVIE \\
\hline
\end{tabular}

(Manuscript received September 16, 1996;

revision accepted for publication December 9, 1996.) 